\title{
Emissions of Diesel - Vegetable Oils Mixtures
}

\author{
Charalampos Arapatsakos \\ Department of Production and Management Engineering, \\ Democritus University of Thrace, Xanthi \\ Greece
}

\section{Introduction}

The industrialization of society, the introduction of motorized vehicles and the explosion of the population are factors contributing toward the growing air pollution problem. Moreover, the exhaust from burning fuels in automobiles, homes and industries is a major source of pollution in the air. Apart from the anthropogenic sources of air pollution there are natural sources as well. Natural sources related to dust from natural source, usually large areas of land with little or no vegetation, the smoke and carbon monoxide from wildfires, volcanic activity etc. Air pollution not only affects the air we breathe, but it also impacts the land and the water. The human health effects of poor air quality are far reaching, but principally affect the body's respiratory system and the cardiovascular system. The human health effects caused by air pollution may range from subtle biochemical and physiological changes to difficulty breathing. It can also cause deaths, aggravated asthma, bronchitis, emphysema, lung and heart diseases to human beings. There are several many types of air pollutant $[1,2]$. These include smog, acid rain, the greenhouse effect and holes in the ozone layer. The atmospheric conditions such as the wind, rain, stability affect the transportation of the air pollutant [3,4]. Furthermore, depending on the geographical location temperature, wind and weather factors, pollution is dispersed differently $[5,6]$. For instance, the wind and rain may effectively dilute pollution to relatively safe concentrations despite a fairly high rate of emissions. In contrast when atmospheric conditions are stable relatively low emissions can cause buildup of pollution to hazardous levels.

The quality of fuel affects diesel engine emissions ( $\mathrm{HC}, \mathrm{CO}, \mathrm{NOx}$ and particulate emissions) very strongly. The fuel that is used in diesel engines is a mixture of hydrocarbons and its boiling temperature is approximately $170^{\circ} \mathrm{C}$ to $360^{\circ} \mathrm{C}$ [4]. Diesel fuel emissions composition and characteristics depend on mixture formation and combustion. In order to compare the quality of fuels the following criteria are tested: ketene rating, density, viscosity, boiling characteristics, aromatics content and sylph content. For environmental compatibility, the fuel must have low density, low content of aromatic compounds, low sylph content and high ketene rating $[6,7,8]$.

One of the most important and renewable sources of energy is biomass. Biomass as a renewable source of energy refers to living and recently dead biological material that can be used as fuel or for industrial production. Some examples of biomass fuels are wood, crops, manure and some garbage. Biomass is a renewable energy source due to photosynthesis. Concretely, with the photosynthesis is committed the solar energy and is changed in 
chemical (energy). At the combustion of biomass the committed solar energy is changed in thermo while the dioxide of coal $\left(\mathrm{CO}_{2}\right)$ returns in the atmosphere, while the inorganic elements that are contained in the ash, enrich the soil with nutritious elements. Nowadays, the use of biomass, covers approximately $4 \%$ of the total energy which is consumed in USA and $45 \%$ of the renewable sources of energy $[9,10,11]$. The most common source of biomass is the wood. For thousands of years people have burned wood for heating and cooking. Another source of biomass is our garbage that comes from plant or animal products. Moreover, various materials of plant origin, as agricultural remains (e.g. straw), material of animal origin, remains from veterinary surgeon units as well as remains of fishery and their sub products, urban waste etc. Wood waste or garbage can be burned to produce steam for making electricity or to provide heat to industries and homes. Biomass can be used for the production of liquid fuel (called biofuel) which is used for the transportation to many countries of Europe, USA etc. [12,13,14]. Bio-diesel is also produced from oily plants (soya, sunflower) animal greases, products of carcasses, and used oils. Some of biomass advantages which make it an attractive source of energy are the following:

1. Reduction of air pollutants. The combustion of biomass has null balance of dioxide of coal $\left(\mathrm{CO}_{2}\right)$ does not contribute in the phenomenon of green house, because the quantities of dioxide of coal $\left(\mathrm{CO}_{2}\right)$ that are released at the combustion of biomass are committed again by the plants for the creation of biomass.

2. Zero existence of sulphur in biomass contributes considerably in the restriction of emissions of dioxide of sulphur $\left(\mathrm{SO}_{2}\right)$ that is in charge of the acid rain.

3. Reduction of dependence from imported fuels, improvement of commercial balance, in the guaranty of energy supply and in the saving of exchange.

4. Sources are commonly available.

5. Sources are locally produced, consequently it increases the occupation to the agriculture places with the use of alternatives cultures (several kinds of cane, sorghum), as well as the creation of alternative markets for the traditional cultures (sunflower etc.) and withholding of population in their hearths.

6. Increase of Biomass production can often mean the restoration of waste land.

Biofuels are liquid or gas fuels which are produced from the biomass. Biomass can replace the conventional mineral fuels, totally or partial in the engines [15].

The major issue is how a four-stroke diesel engine behaves on the side of pollutants and operation, when it uses mixed fuel of diesel - vegetable oils.

\section{Instrumentation and experimental results}

In the experiment stage has been used directly used vegetable oil (used sunflower oil that emanated from cooking) in the mixture of diesel in to a four - stroke diesel engine. Specifically it has been used diesel, mixture diesel-5\% used vegetable oil (u5), diesel-10 used vegetable oil (u10), diesel-20\% used vegetable oil (u20), diesel-30\% used vegetable oil (u30), diesel-40\% used vegetable oil (u40), diesel-50\% used vegetable oil (u50) in a four-stroke diesel air-cooled engine named Ruggerini type RD-80, volume 377cc, and power $8.2 \mathrm{hp} / 3000 \mathrm{rpm}$, who was connected with a pump of water centrifugal. Measurements were made when the engine was function on 1000, 1500, 2000 and 2500rpm.

During the experiments, it has been counted:

- The percent of $\mathrm{CO}$

- The ppm of HC 
- The ppm of NO

- The percent of smoke

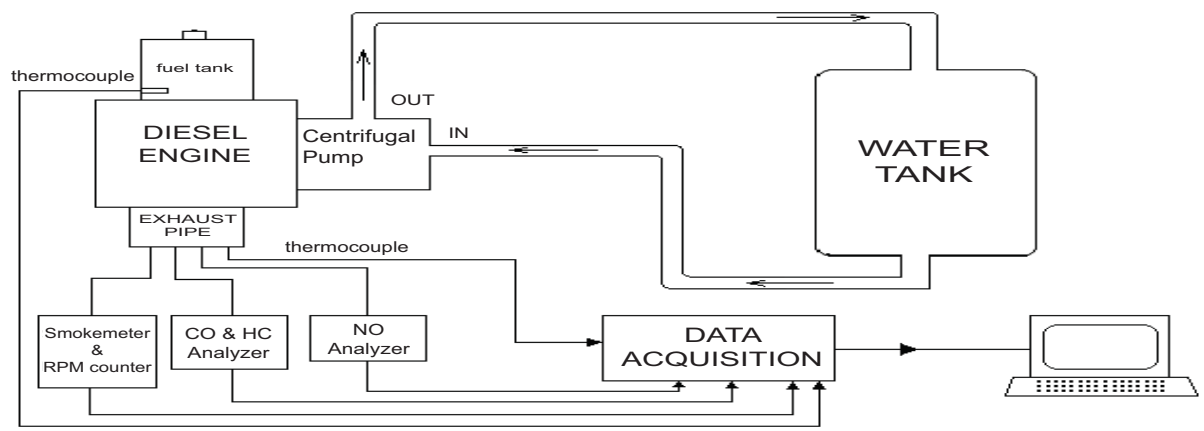

Fig. 1. Experimental Layout

The measurement of rounds/min of the engine was made by a portable tachometer (Digital photo/contact tachometer) named LTLutron DT-2236. Smoke was measured by a specifically measurement device named SMOKE MODULE EXHAUST GAS ANALYSER MOD 9010/M, which has been connected to a PC unit. The CO and HC emissions have been measured by HORIBA Analyzer MEXA-324 GE. The NO emissions were measured by a Single GAS Analyser SGA92-NO.

\subsection{Used vegetable oil}

The experimental results are shown at the following tables and figures [16]:

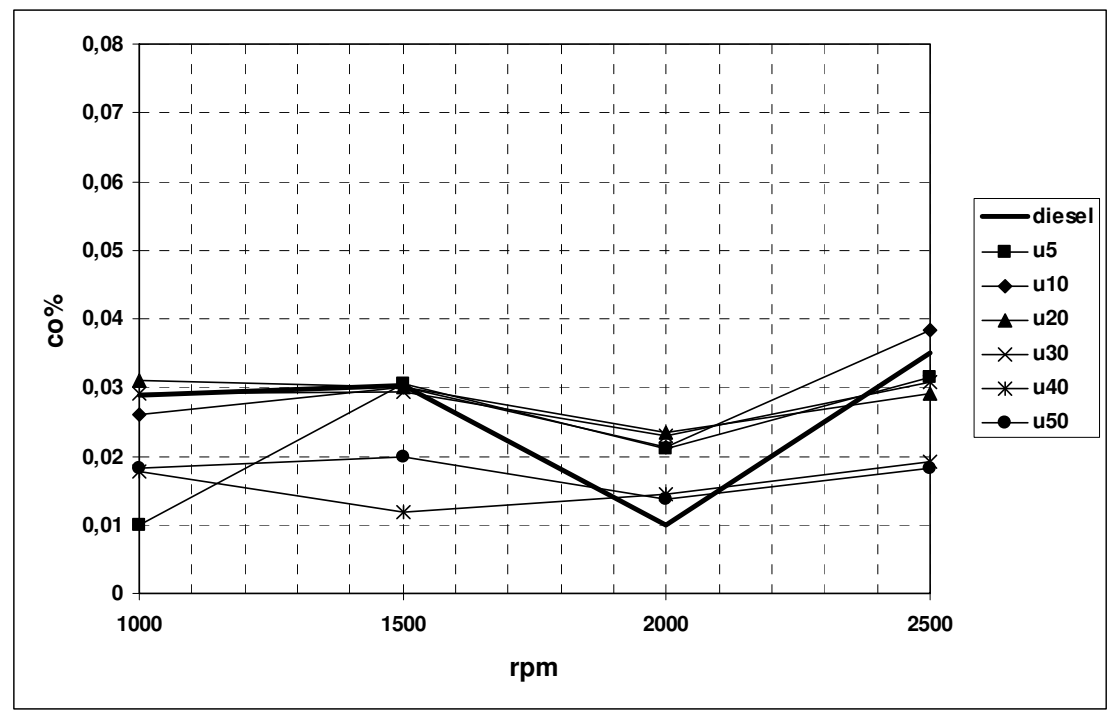

Fig. 2. The $\mathrm{CO}$ variation on different rpm regarding to the mixture 


\begin{tabular}{|c|c|c|c|c|c|c|c|}
\hline \multirow{2}{*}{$\mathbf{r p m}$} & \multicolumn{7}{|c|}{ CO \% } \\
\cline { 2 - 8 } & diesel & $\mathbf{u 5}$ & $\mathbf{u 1 0}$ & $\mathbf{u 2 0}$ & $\mathbf{u 3 0}$ & $\mathbf{u 4 0}$ & $\mathbf{u 5 0}$ \\
\hline $\mathbf{1 0 0 0}$ & 0,02898 & 0,01000 & 0,026081 & 0,030985 & 0,029143 & 0,017823 & 0,018223 \\
\hline $\mathbf{1 5 0 0}$ & 0,03039 & 0,03059 & 0,030043 & 0,029979 & 0,029310 & 0,011818 & 0,019767 \\
\hline $\mathbf{2 0 0 0}$ & 0,01000 & 0,02108 & 0,021379 & 0,023500 & 0,023059 & 0,014483 & 0,013624 \\
\hline $\mathbf{2 5 0 0}$ & 0,03508 & 0,03145 & 0,038315 & 0,029120 & 0,030713 & 0,019111 & 0,018298 \\
\hline
\end{tabular}

Table 1 . The $\mathrm{CO}$ average value variation on different rpm regarding to the mixture

\begin{tabular}{|c|c|c|c|c|c|c|c|}
\hline \multirow{2}{*}{ rpm } & \multicolumn{7}{|c|}{ HC (ppm) } \\
\cline { 2 - 8 } & diesel & $\mathbf{u 5}$ & $\mathbf{u 1 0}$ & $\mathbf{u 2 0}$ & $\mathbf{u 3 0}$ & $\mathbf{u 4 0}$ & $\mathbf{u 5 0}$ \\
\hline $\mathbf{1 0 0 0}$ & 2,535343 & 8,844156 & 5,653105 & 5,246253 & 5,124364 & 2,147903 & 2,974304 \\
\hline $\mathbf{1 5 0 0}$ & 13,31714 & 24,99127 & 12,87527 & 13,15385 & 9,358621 & 2,934461 & 6,714588 \\
\hline $\mathbf{2 0 0 0}$ & 7,131223 & 8,326797 & 12,67026 & 9,195652 & 13,79747 & 5,267241 & 4,936681 \\
\hline $\mathbf{2 5 0 0}$ & 10,96128 & 16,63420 & 17,30454 & 16,94635 & 6,706013 & 6,598698 & 6,759574 \\
\hline
\end{tabular}

Table 2 . The HC average value variation on different rpm regarding to the mixture

\begin{tabular}{|c|c|c|c|c|c|c|c|}
\hline rpm & \multicolumn{7}{|c|}{ NO (ppm) } \\
\hline & diesel & $\mathbf{u 5}$ & $\mathbf{u 1 0}$ & $\mathbf{u 2 0}$ & $\mathbf{u 3 0}$ & $\mathbf{u 4 0}$ & $\mathbf{u 5 0}$ \\
\hline $\mathbf{1 0 0 0}$ & 518,210 & 771,001 & 696,827 & 495,603 & 380,361 & 349,140 & 207,760 \\
\hline $\mathbf{1 5 0 0}$ & 739,366 & 754,126 & 913,037 & 771,607 & 723,381 & 872,06 & 582,908 \\
\hline $\mathbf{2 0 0 0}$ & 762,155 & 834,334 & 520,485 & 760,936 & 839,268 & 928,337 & 720,505 \\
\hline $\mathbf{2 5 0 0}$ & 795,461 & 946,349 & 518,287 & 710,402 & 864,585 & 674,432 & 847,835 \\
\hline
\end{tabular}

Table 3. The NO average value variation on different rpm regarding to the mixture

\begin{tabular}{|c|c|c|c|c|c|c|c|}
\hline \multirow{2}{*}{ rpm } & \multicolumn{7}{|c|}{ \% smoke } \\
\cline { 2 - 8 } & diesel & $\mathbf{u 5}$ & $\mathbf{u 1 0}$ & $\mathbf{u 2 0}$ & $\mathbf{u} 30$ & $\mathbf{u 4 0}$ & $\mathbf{u 5 0}$ \\
\hline $\mathbf{1 0 0 0}$ & 3,262370 & 4,870779 & 5,966167 & 16,43362 & 12,26745 & 15,7298 & 11,32741 \\
\hline $\mathbf{1 5 0 0}$ & 7,100651 & 8,174236 & 5,768602 & 7,652778 & 5,56423 & 9,206977 & 13,05011 \\
\hline $\mathbf{2 0 0 0}$ & 5,688865 & 7,619826 & 4,704957 & 6,151304 & 4,948101 & 4,351724 & 9,59869 \\
\hline $\mathbf{2 5 0 0}$ & 29,00617 & 23,21970 & 25,67279 & 16,86674 & 14,59399 & 17,48286 & 15,87915 \\
\hline
\end{tabular}

Table 4 . The $\%$ smoke average value variation on different rpm regarding to the mixture

From figure 2 it is clear that the more constant behaviour appears in the mixture u40, while the best behaviour is appears in the case diesel/1500rpm. From figure 3 it can be noticed the biggest reduction of $\mathrm{HC}$ regarding to diesel in case of mixture u40. From figure 4 it can be noticed the biggest reduction of NO regarding to diesel in the case of mixture u40. From figure 5 it can be seen the biggest reduction for u 40 until the case u40/1000rpm. From the above figures it is clear that the use of different mixtures can constitute changes to $\mathrm{CO}, \mathrm{HC}$, $\mathrm{NO}$ and smoke too. It is also important the fact that there was no changes in the rounds of the engine, as well as in the supply of water at the use of mixtures. Finally as far as the consumption is concerned, did not observed changes with the use of different mixtures. 


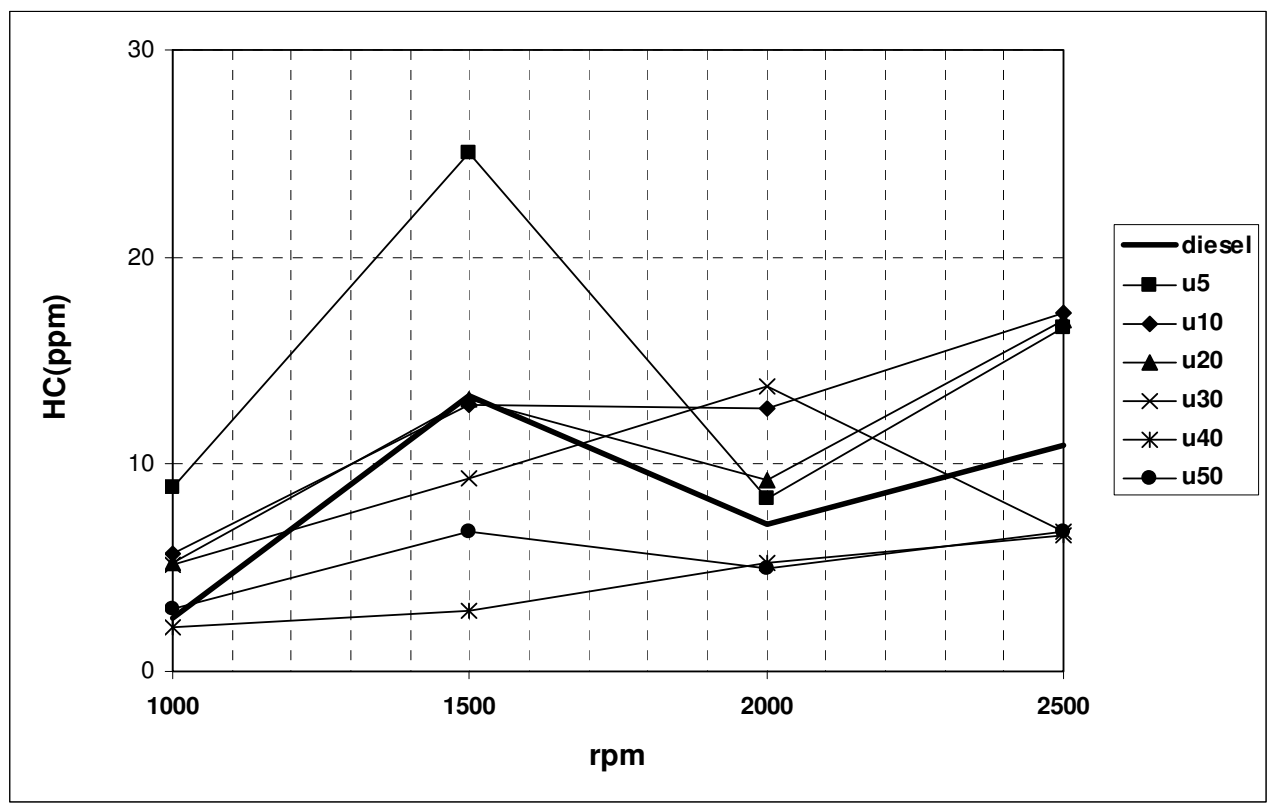

Fig. 3. The HC variation on different rpm regarding to the mixture

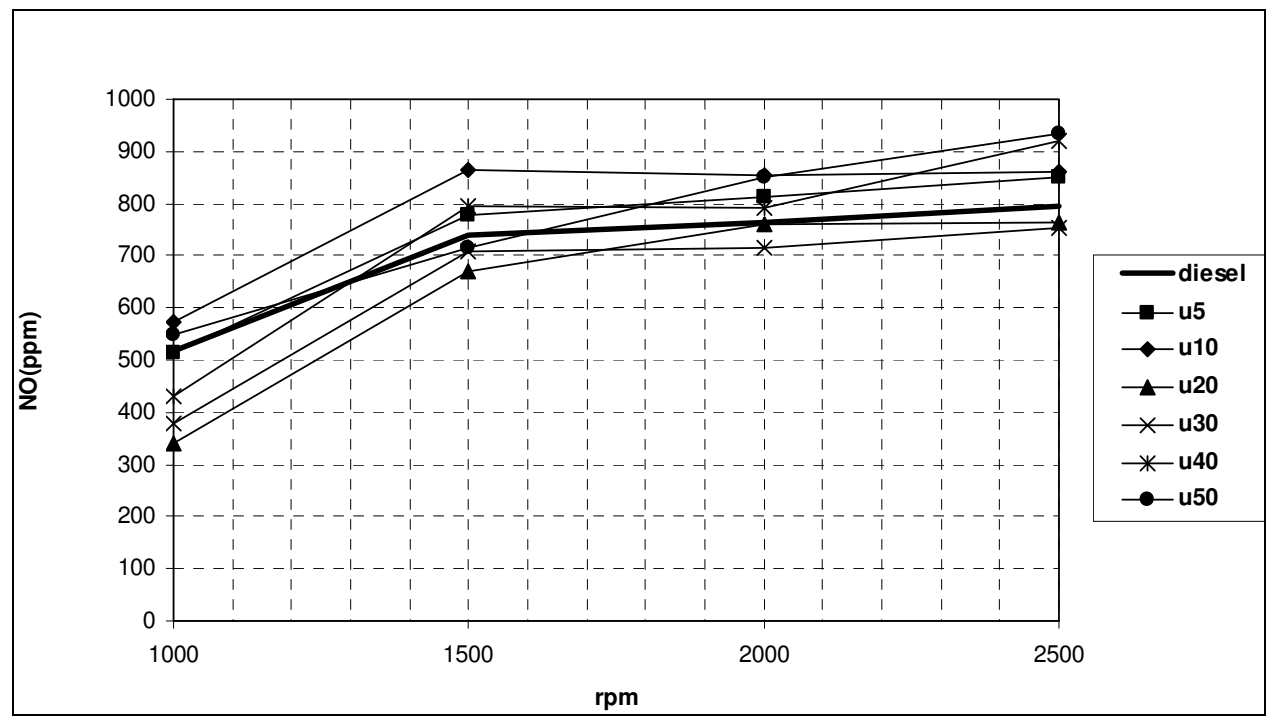

Fig. 4. The NO variation on different rpm regarding to the mixture

The use of mixtures of diesel-vegetable oil has as result change of gas emissions with better behaviour in the mixture $\mathrm{u} 40$. It is important, that is not presented reduction of power of engine from the combustion of the mixtures. 


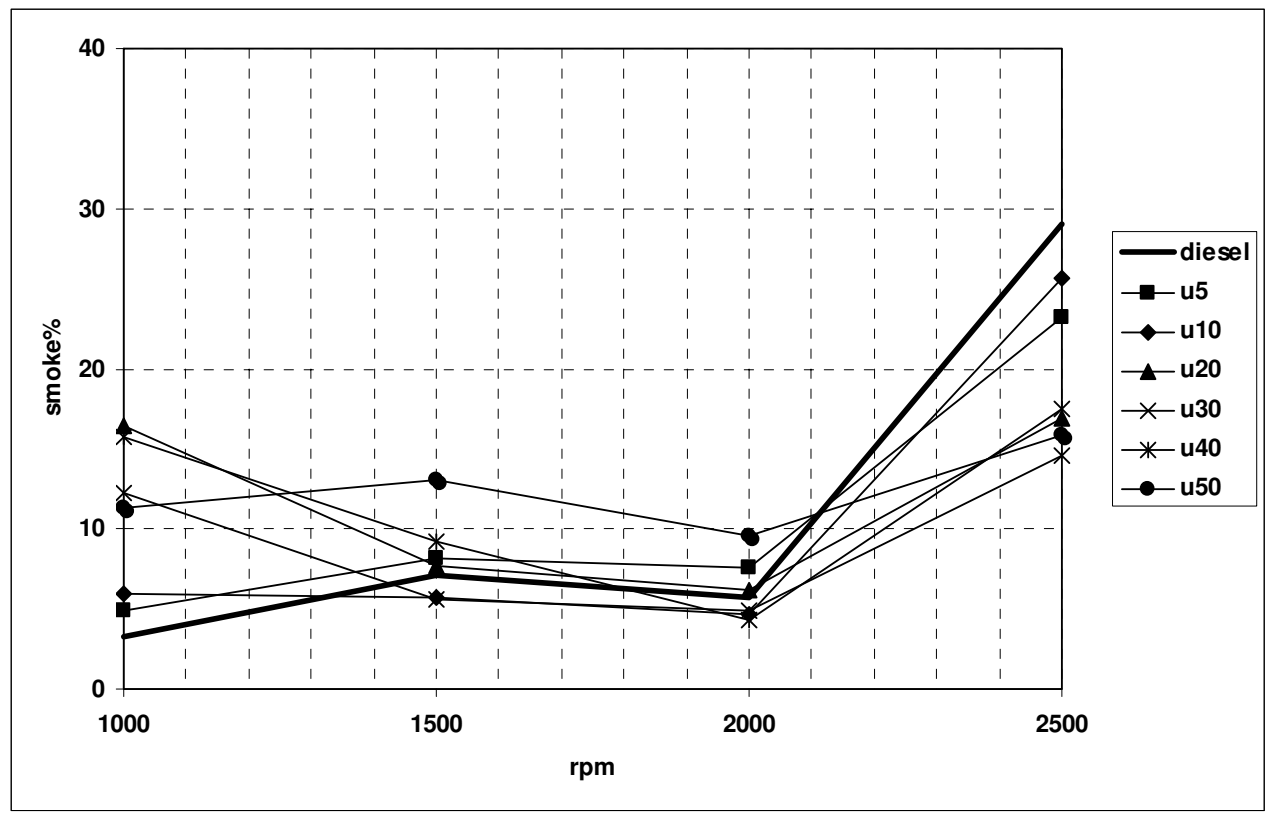

Fig. 5. The smoke variation on different rpm regarding to the mixture

\subsection{Maize oil}

In the experiment stage has been used directly maize oil in the mixture of diesel in to a four - stroke diesel engine. Specifically it has been used diesel, mixture diesel-5\% maize oil ( $\mathrm{k} 5$ ), diesel-10\% maize oil (k10), diesel-20\% maize oil (k20), diesel-30\% maize oil (k30), diesel-40\% maize oil (k40), diesel-50\% maize oil (k50) in a four-stroke diesel engine [17]:

\begin{tabular}{|c|c|c|c|c|c|c|c|}
\hline \multirow{2}{*}{$\mathbf{r p m}$} & \multicolumn{7}{|c|}{ CO \% } \\
\cline { 2 - 8 } & diesel & $\mathbf{k 5}$ & $\mathbf{k 1 0}$ & $\mathbf{k 2 0}$ & $\mathbf{k 3 0}$ & $\mathbf{k 4 0}$ & $\mathbf{k 5 0}$ \\
\hline $\mathbf{1 0 0 0}$ & 0,0289 & 0,0310 & 0,0309 & 0,0309 & 0,0319 & 0,0397 & 0,0345 \\
\hline $\mathbf{1 5 0 0}$ & 0,0303 & 0,0302 & 0,0304 & 0,0311 & 0,0345 & 0,0211 & 0,0288 \\
\hline $\mathbf{2 0 0 0}$ & 0,01 & 0,0280 & 0,0232 & 0,0284 & 0,0274 & 0,0281 & 0,0219 \\
\hline $\mathbf{2 5 0 0}$ & 0,0350 & 0,0244 & 0,0317 & 0,0296 & 0,0324 & 0,0305 & 0,0292 \\
\hline
\end{tabular}

Table 5. The $\mathrm{CO}$ average value variation on different $\mathrm{rpm}$ regarding to the mixture

\begin{tabular}{|c|c|c|c|c|c|c|c|}
\hline \multirow{2}{*}{ rpm } & \multicolumn{7}{|c|}{ HC (ppm) } \\
\cline { 2 - 8 } & diesel & $\mathbf{k 5}$ & $\mathbf{k 1 0}$ & $\mathbf{k 2 0}$ & $\mathbf{k 3 0}$ & $\mathbf{k 4 0}$ & $\mathbf{k 5 0}$ \\
\hline $\mathbf{1 0 0 0}$ & 2,535 & 14,937 & 6,244 & 10,326 & 3,406 & 5,358 & 9,167 \\
\hline $\mathbf{1 5 0 0}$ & 13,31 & 21,485 & 9,236 & 17,997 & 14,718 & 0,449 & 17,197 \\
\hline $\mathbf{2 0 0 0}$ & 7,131 & 3,184 & 13,970 & 15,965 & 8,402 & 8,502 & 12,913 \\
\hline $\mathbf{2 5 0 0}$ & 10,961 & 16,347 & 18,884 & 23,556 & 30,551 & 7,451 & 17,712 \\
\hline
\end{tabular}

Table 6. The HC average value variation on different rpm regarding to the mixture 


\begin{tabular}{|c|c|c|c|c|c|c|c|}
\hline \multirow{2}{*}{ rpm } & \multicolumn{7}{|c|}{ NO (ppm) } \\
\cline { 2 - 8 } & diesel & k5 & $\mathbf{k 1 0}$ & $\mathbf{k 2 0}$ & $\mathbf{k 3 0}$ & $\mathbf{k 4 0}$ & $\mathbf{k 5 0}$ \\
\hline $\mathbf{1 0 0 0}$ & 518,210 & 771,001 & 696,827 & 495,603 & 380,361 & 349,140 & 207,760 \\
\hline $\mathbf{1 5 0 0}$ & 739,366 & 754,126 & 913,037 & 771,607 & 723,381 & 872,06 & 582,908 \\
\hline $\mathbf{2 0 0 0}$ & 762,155 & 834,334 & 520,485 & 760,936 & 839,268 & 928,337 & 720,505 \\
\hline $\mathbf{2 5 0 0}$ & 795,461 & 946,349 & 518,287 & 710,402 & 864,585 & 674,432 & 847,835 \\
\hline
\end{tabular}

Table 7 . The NO average value variation on different rpm regarding to the mixture

\begin{tabular}{|c|c|c|c|c|c|c|c|}
\hline \multirow{2}{*}{$\mathbf{r p m}$} & \multicolumn{7}{|c|}{ \% smoke } \\
\cline { 2 - 8 } & diesel & $\mathbf{k 5}$ & $\mathbf{k 1 0}$ & $\mathbf{k 2 0}$ & $\mathbf{k 3 0}$ & $\mathbf{k 4 0}$ & $\mathbf{k 5 0}$ \\
\hline $\mathbf{1 0 0 0}$ & 3,262 & 12,722 & 7,301 & 7,488 & 16,623 & 7,200 & 26,232 \\
\hline $\mathbf{1 5 0 0}$ & 7,100 & 10,924 & 5,487 & 6,547 & 14,850 & 12,141 & 24,035 \\
\hline $\mathbf{2 0 0 0}$ & 5,688 & 18,679 & 4,001 & 6,588 & 9,936 & 14,071 & 18,884 \\
\hline $\mathbf{2 5 0 0}$ & 29,006 & 28,282 & 21,848 & 15,730 & 17,579 & 13,438 & 14,265 \\
\hline
\end{tabular}

Table 8 . The $\%$ smoke average value variation on different rpm regarding to the mixture

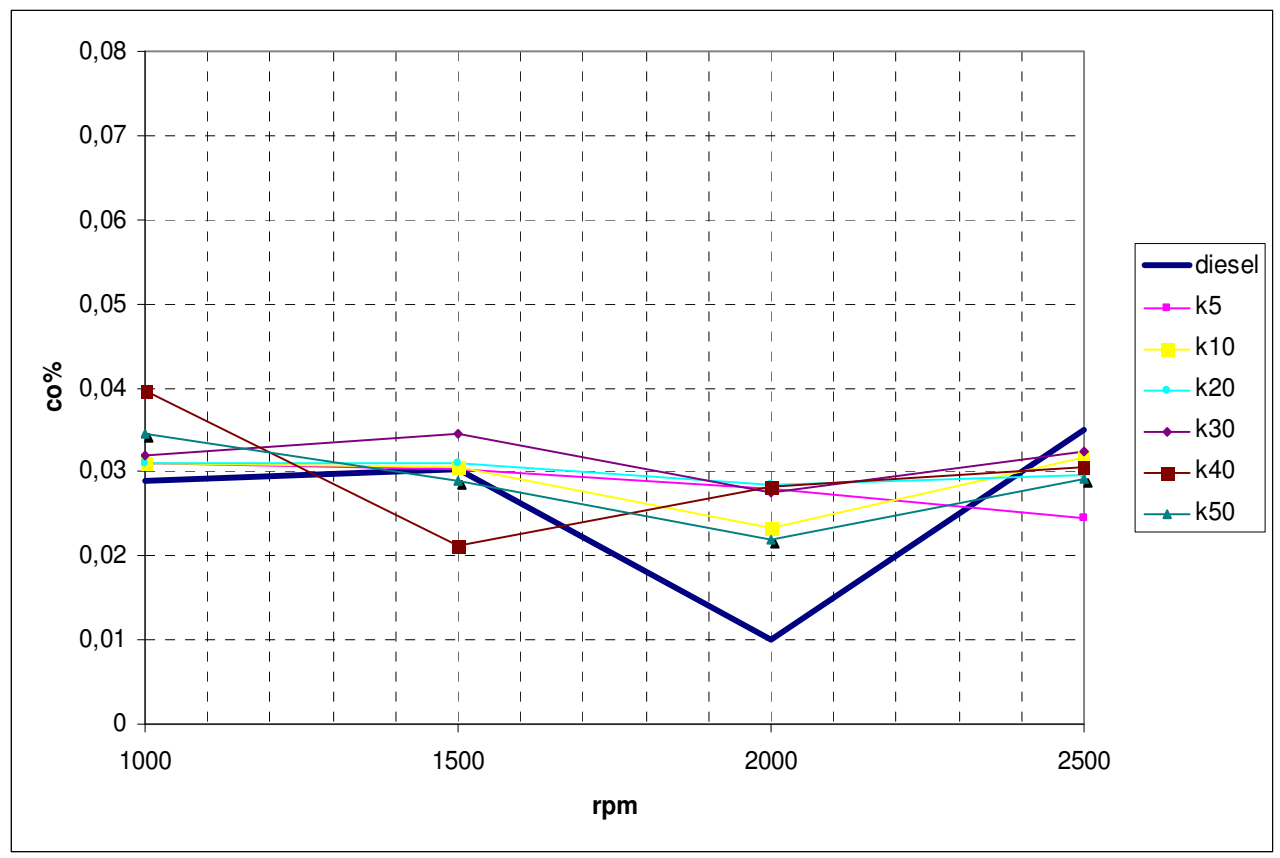

Fig. 6. The $\mathrm{CO}$ variation on different rpm regarding to the mixture 


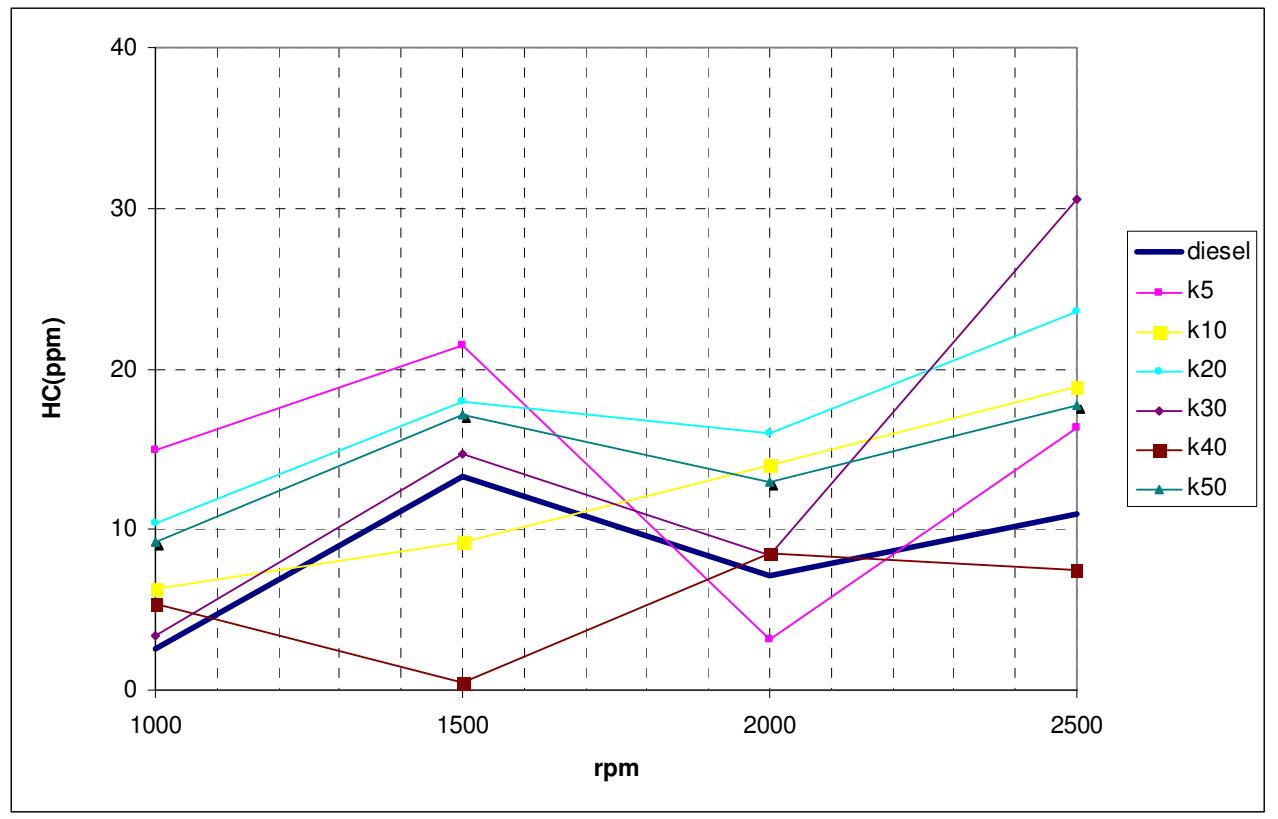

Fig. 7. The HC variation on different rpm regarding to the mixture

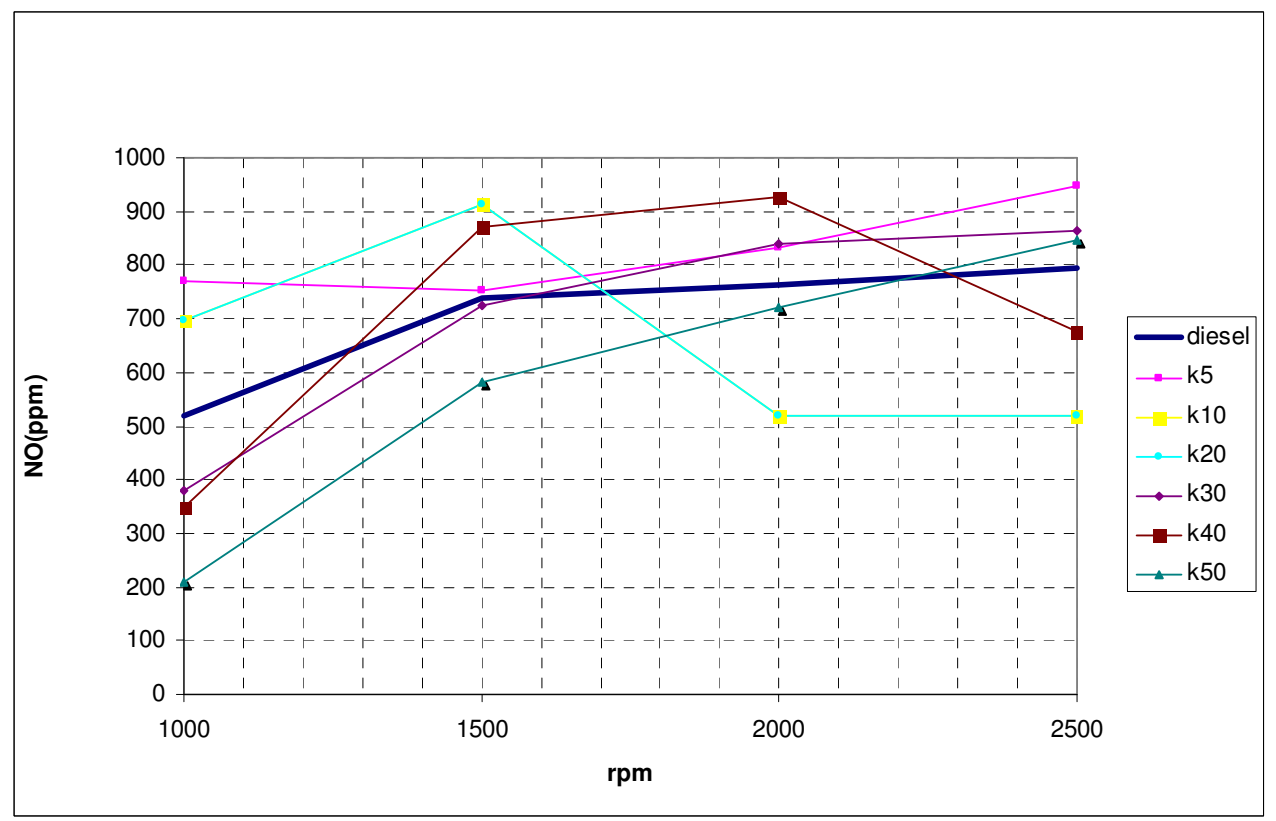

Fig. 8. The NO variation on different rpm regarding to the mixture 


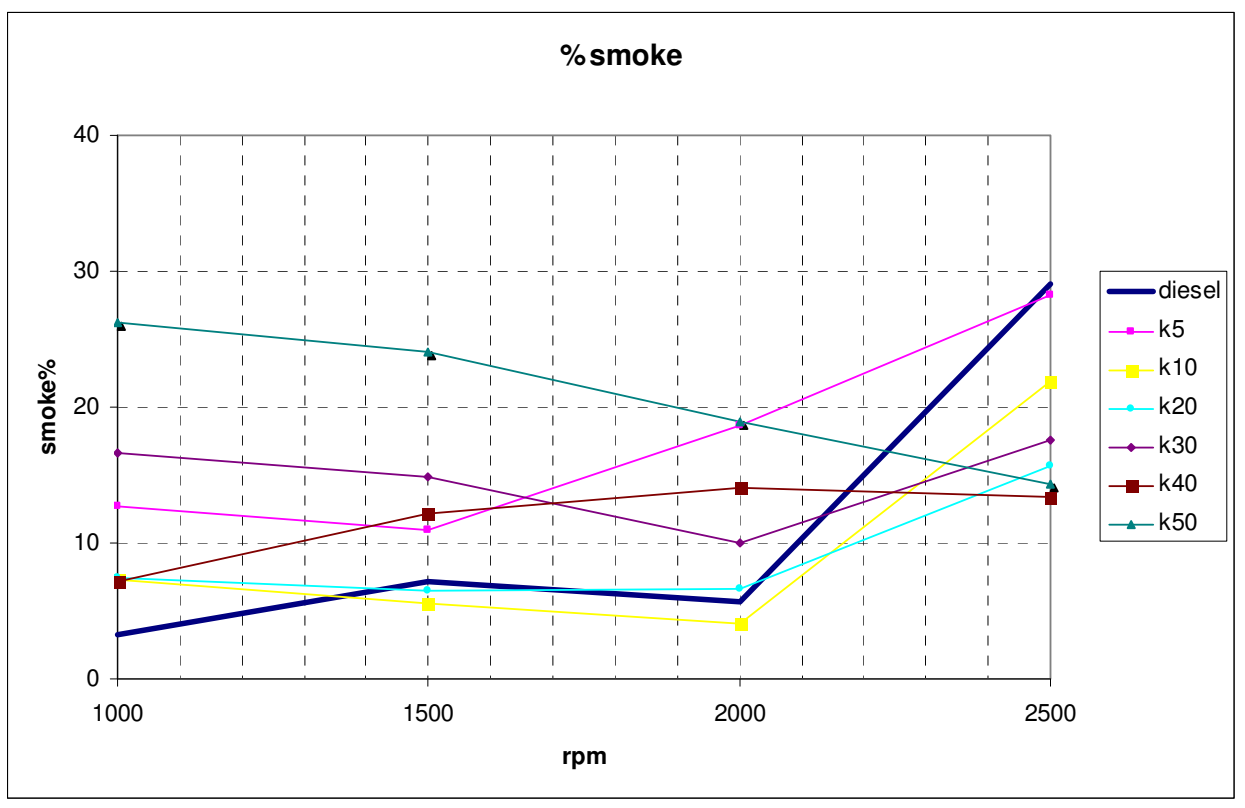

Fig. 9. The smoke variation on different rpm regarding to the mixture

From figure 6 it is clear that when the maize oil is increased on the fuel regarding to diesel, it appears an increase of CO, except in the case k40/1500rpm. From figure 7 it can be noticed the biggest reduction of $\mathrm{HC}$ regarding to diesel in case of k40/1500rpm. From figure 8 it can be noticed the biggest reduction of NO regarding to diesel in the case of k20/2000-2500rpm. From figure 9 it can be noticed the biggest reduction for k10/1500-2000rpm. From the above figures it is clear that the use of different mixtures can constitute changes to $\mathrm{CO}, \mathrm{HC}$, NO and smoke too. It is also important the fact that there was no changes in the rounds of the engine, as well as in the supply of water at the use of mixtures. Finally as far as the consumption is concerned, did not observed changes with the use of different mixtures. The use of mixture of diesel and maize oil has the following impacts:

- $\quad$ About CO it can be noticed that when the maize oil is increased on the fuel regarding to diesel, it appears a decrease of CO, except in the case k40/1500rpm.

- About HC it can be noticed the biggest reduction of $\mathrm{HC}$ regarding to diesel in case of k40/1500rpm

- The biggest reduction of NO regarding to Diesel is noticed in the case of k20/20002500rpm.

- $\quad$ The smoke it can be noticed the biggest reduction for k10/1500-2000rpm

\subsection{Cotton oil}

In the experiment stage has been used directly cotton oil in the mixture of diesel in to a four - stroke Diesel engine and not elaborated in the figure of bio-diesel. Specifically it has been used diesel, mixture diesel- $10 \%$ cotton oil(B10), diesel- $20 \%$ cotton oil(B20), diesel- 30\% cotton oil (B30), diesel- 40\% cotton oil (B40), diesel- 50\% cotton oil (B50) in a four-stroke diesel engine [18]: 
The experimental results are shown at the following tables and figures:

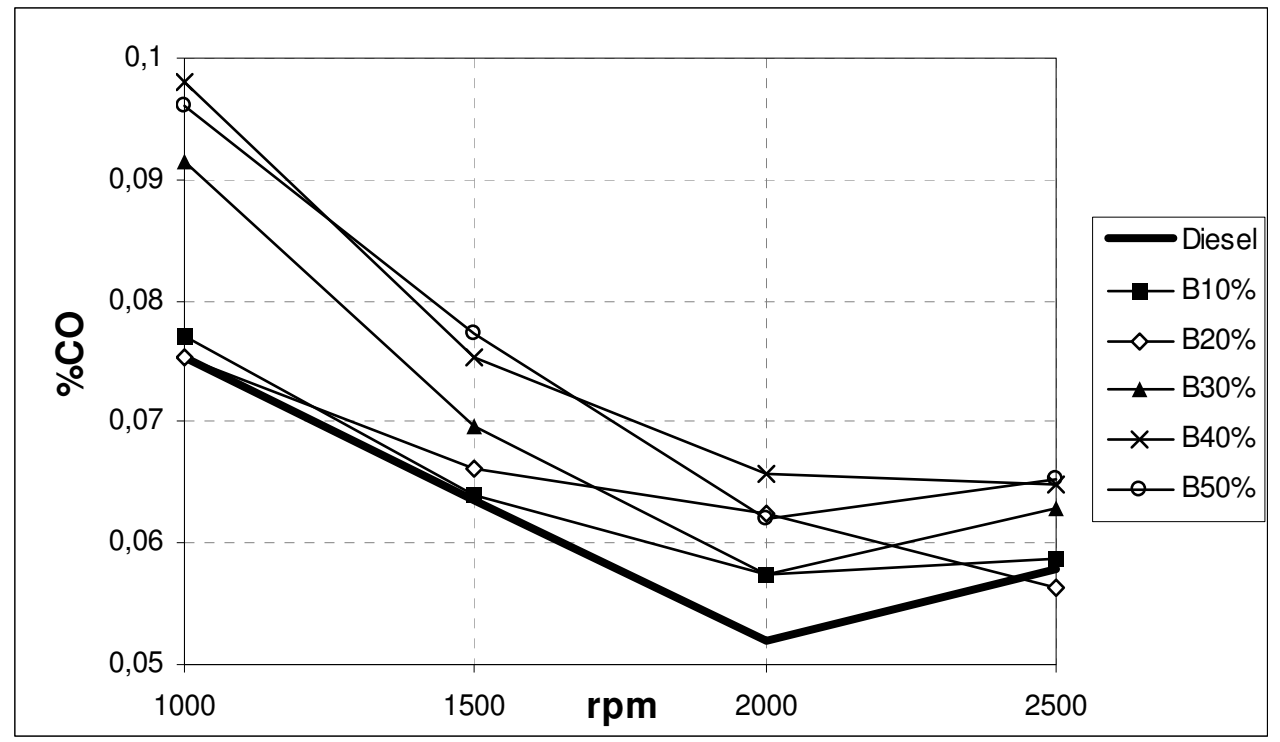

Fig. 10. The $\mathrm{CO}$ variation on different rpm regarding to the mixture

From figure 10 it is clear that when the cotton oil is increased on the fuel regarding to Diesel, it appears an increasement of $\mathrm{CO}$.

\begin{tabular}{|c|c|c|c|c|c|c|}
\hline \multirow{2}{*}{ rpm } & \multicolumn{7}{|c|}{ \% CO } \\
\cline { 2 - 7 } & Diesel & B10 & B20 & B30 & B40 & B50 \\
\hline 1000 & 0,075 & 0,076 & 0,075 & 0,091 & 0,098 & 0,095 \\
\hline 1500 & 0,063 & 0,064 & 0,066 & 0,069 & 0,075 & 0,077 \\
\hline 2000 & 0,052 & 0,057 & 0,062 & 0,057 & 0,065 & 0,061 \\
\hline 2500 & 0,057 & 0,058 & 0,056 & 0,062 & 0,064 & 0,065 \\
\hline
\end{tabular}

Table 9. The $\mathrm{CO}$ average value variation on different rpm regarding to the mixture

\begin{tabular}{|c|c|c|c|c|c|c|}
\hline \multirow{2}{*}{ rpm } & \multicolumn{7}{|c|}{ HC (ppm) } \\
\cline { 2 - 7 } & Diesel & B10 & B20 & B30 & B40 & B50 \\
\hline 1000 & 30,78 & 35,86 & 39,04 & 39,05 & 14,86 & 46,64 \\
\hline 1500 & 62,86 & 41,18 & 35,59 & 48,74 & 53,84 & 51,34 \\
\hline 2000 & 125,52 & 83,84 & 101,38 & 109,07 & 76,42 & 142,94 \\
\hline 2500 & 78,26 & 84,93 & 169,34 & 103,64 & 167,82 & 105,80 \\
\hline
\end{tabular}

Table 10. The HC average value variation on different rpm regarding to the mixture 


\begin{tabular}{|c|c|c|c|c|c|c|}
\hline \multirow{2}{*}{ rpm } & \multicolumn{7}{|c|}{ NO (ppm) } \\
\cline { 2 - 7 } & Diesel & B10 & B20 & B30 & B40 & B50 \\
\hline 1000 & 439,67 & 471,17 & 464,34 & 361,59 & 318,85 & 320,47 \\
\hline 1500 & 649,65 & 660,83 & 626,78 & 611,71 & 565,26 & 522,16 \\
\hline 2000 & 710,41 & 688,75 & 679,64 & 687,06 & 710,18 & 798,96 \\
\hline 2500 & 868,88 & 930,50 & 919,53 & 919,08 & 987,35 & 947,80 \\
\hline
\end{tabular}

Table 11. The no average value variation on different rpm regarding to the mixture

\begin{tabular}{|c|c|c|c|c|c|c|}
\hline \multirow{2}{*}{ rpm } & \multicolumn{7}{|c|}{ \%smoke } \\
\cline { 2 - 7 } & Diesel & B10 & B20 & B30 & B40 & B50 \\
\hline 1000 & 7,72 & 5,76 & 6,36 & 13,89 & 12,88 & 13,35 \\
\hline 1500 & 5,81 & 3,16 & 5,41 & 10,72 & 12,17 & 13,62 \\
\hline 2000 & 5,24 & 3,62 & 4,45 & 7,59 & 7,28 & 7,70 \\
\hline 2500 & 10,98 & 7,94 & 9,93 & 7,92 & 9,62 & 9,01 \\
\hline
\end{tabular}

Table 12 . The $\%$ smoke average value variation on different rpm regarding to the mixture

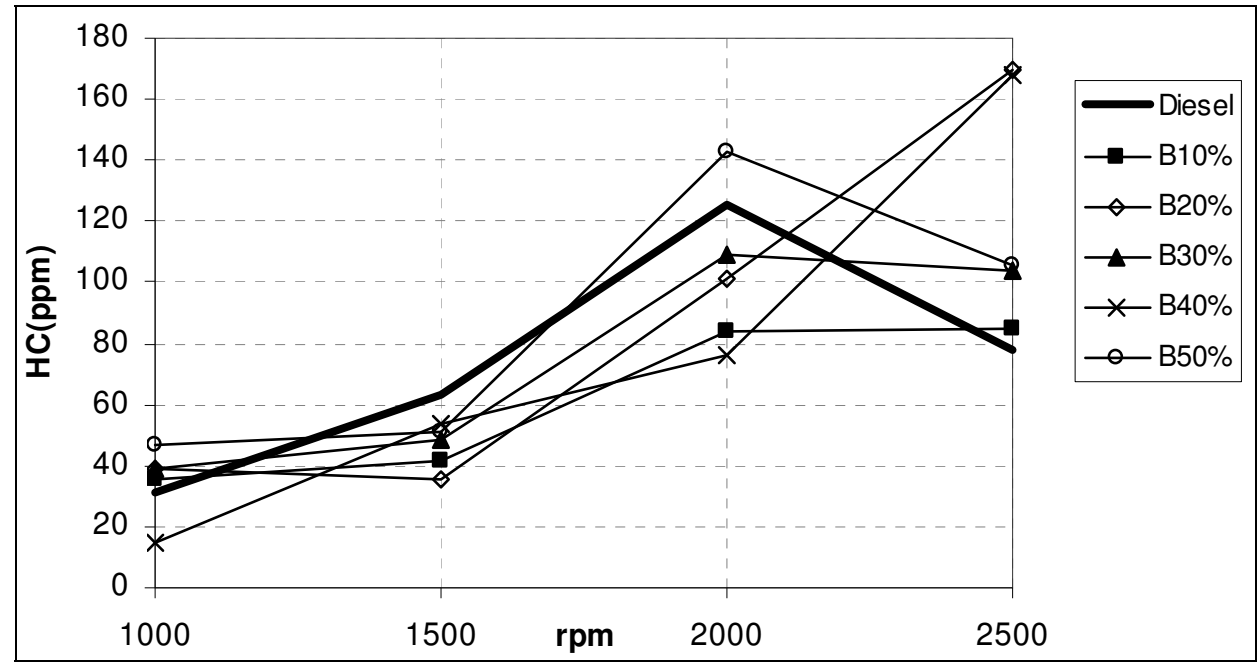

Fig. 11. The HC variation on different rpm regarding to the mixture

From figure 11 it can be noticed the biggest reduction of $\mathrm{HC}$ regarding to Diesel in case of the mixture B20/1500 rpm and in the case of the mixture B40/2000 rpm.

From figure 12 it can be noticed the biggest reduction of $\mathrm{NO}$ regarding to Diesel in the cases of the mixture B40/1000 rpm, B50/1000 rpm and B50/1500 rpm too.

From figure 13 it can be seen the reduction of smoke regarding to Diesel in case of the mixture B10 and B20 at all rounds per minute. It can also be noticed the reduction of smoke in the case of B30, B40, B50/2500 rpm. Finally it can be seen an increasement of the mixture B30, B40, B50 at all rounds regarding to Diesel. From the above figures it is clear that the use of different mixtures can constitute changes to $\mathrm{CO}, \mathrm{HC}, \mathrm{NO}$ and smoke too. 


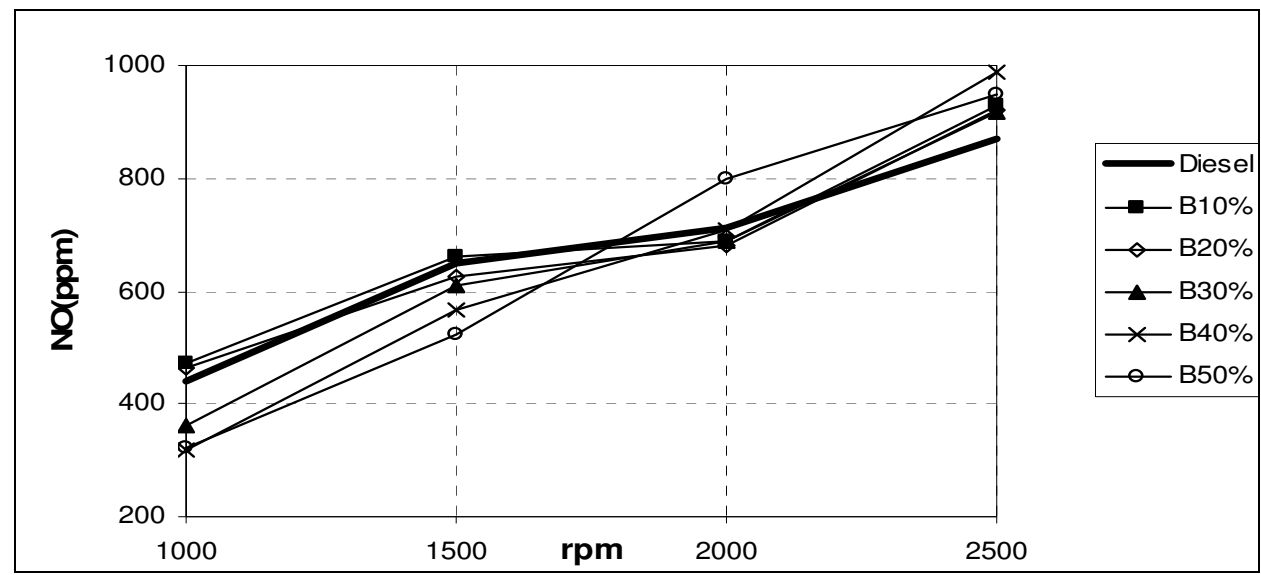

Fig. 12. The NO variation on different rpm regarding to the mixture

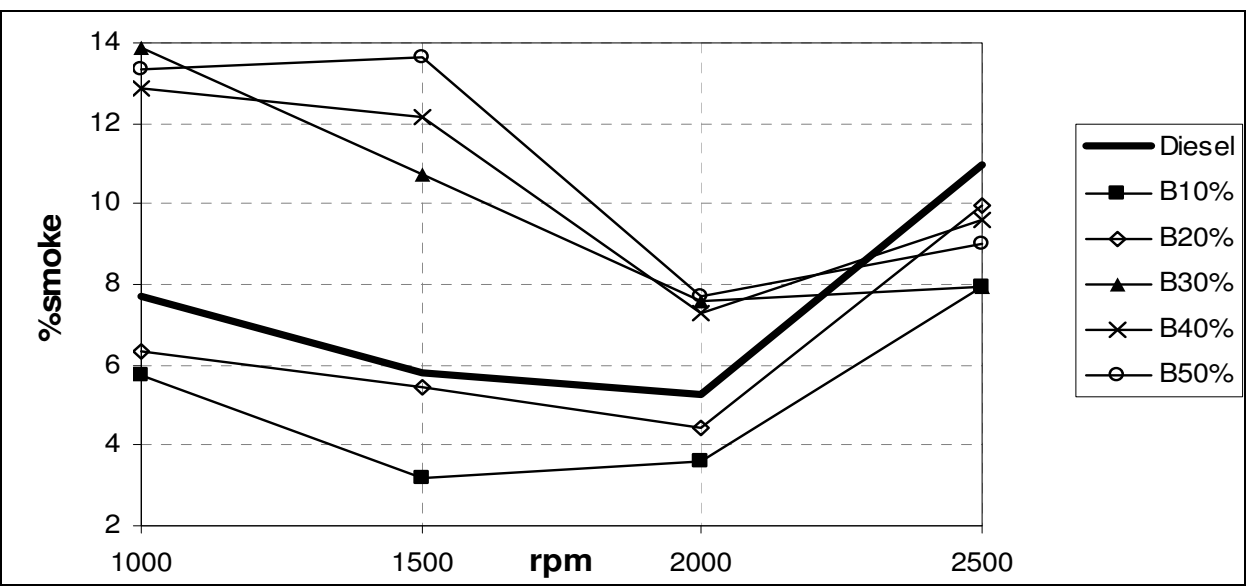

Fig. 13. The smoke variation on different rpm regarding to the mixture

It is also important the fact that there was no changes in the turns of engine, as well as in the supply of water at the use of mixtures. Finally as far as the consumption is concerned, did not exist changes with the use of different mixtures.The use of mixture of Diesel and Cotton Oil has the following impacts:

- $\quad$ About CO it can be noticed an increasement when the cotton oil is used as a fuel.

- $\quad$ About HC it can be noticed a reduction at $1500 \mathrm{rpm}$ and particularly bigger reduction in the use of B20. It also appears reduction of the $\mathrm{HC}$ for all the mixture at $2000 \mathrm{rpm}$ with the exception of B50. Finally about the HC, for all the mixture at $2500 \mathrm{rpm}$ is observed increase of $\mathrm{HC}$ regarding to Diesel.

- $\quad$ About NO has been noticed a reduction at $1000 \mathrm{rpm}$ and $1500 \mathrm{rpm}$ for all the mixtures. A small reduction appeared for all the mixtures at $2500 \mathrm{rpm}$ with the exception of B50, regarding to Diesel. Finally about the NO for all the mixtures appeared increase at 2500 rpm regarding to Diesel. 
- About the smoke it can be noticed a reduction of the mixture of B20 and B10, but it appears an increasement for all other mixture in any round regarding to Diesel, with the exception of $2500 \mathrm{rpm}$, in where all the mixture appear a reduction.

\subsection{Olive seed oil}

In the experiment stage has been used directly cotton oil in the mixture of diesel in to a four - stroke Diesel engine. Specifically it has been used diesel, mixture diesel-5\% olive seed oil (Pyrin5\%), diesel-10\% olive seed oil (Pyrin10\%), diesel-20\% olive seed oil (Pyrin20\%), diesel$30 \%$ olive seed oil (Pyrin30\%), diesel-40\% olive seed oil (Pyrin40\%), diesel-50\% olive seed oil (Pyrin50\%) in a four-stroke diesel engine [19]:

The experimental results are shown at the following tables and figures:

\begin{tabular}{|c|c|c|c|c|c|c|c|}
\hline \multirow{2}{*}{$\mathbf{r p m}$} & \multicolumn{7}{|c|}{ CO \% } \\
\cline { 2 - 8 } & diesel & $\begin{array}{c}\text { Pyrin } \\
\mathbf{5 \%}\end{array}$ & $\begin{array}{c}\text { Pyrin } \\
\mathbf{1 0 \%}\end{array}$ & $\begin{array}{c}\text { Pyrin } \\
\mathbf{2 0} \%\end{array}$ & $\begin{array}{c}\text { Pyrin } \\
\mathbf{3 0} \%\end{array}$ & $\begin{array}{c}\text { Pyrin } \\
\mathbf{4 0} \%\end{array}$ & $\begin{array}{c}\text { Pyrin } \\
\mathbf{5 0} \%\end{array}$ \\
\hline $\mathbf{1 0 0 0}$ & 0,056 & 0,056 & 0,054 & 0,060 & 0,053 & 0,053 & 0,048 \\
\hline $\mathbf{1 5 0 0}$ & 0,055 & 0,044 & 0,038 & 0,055 & 0,040 & 0,041 & 0,036 \\
\hline $\mathbf{2 0 0 0}$ & 0,043 & 0,038 & 0,031 & 0,050 & 0,031 & 0,036 & 0,030 \\
\hline
\end{tabular}

Table 13. The $\mathrm{CO}$ average value variation on different rpm regarding to the mixture

\begin{tabular}{|c|c|c|c|c|c|c|c|}
\hline \multirow{2}{*}{ rpm } & \multicolumn{7}{|c|}{ HC (ppm) } \\
\cline { 2 - 8 } & diesel & $\begin{array}{c}\text { Pyrin } \\
\mathbf{5} \%\end{array}$ & $\begin{array}{c}\text { Pyrin } \\
\mathbf{1 0} \%\end{array}$ & $\begin{array}{c}\text { Pyrin } \\
\mathbf{2 0} \%\end{array}$ & $\begin{array}{c}\text { Pyrin } \\
\mathbf{3 0} \%\end{array}$ & $\begin{array}{c}\text { Pyrin } \\
\mathbf{4 0} \%\end{array}$ & $\begin{array}{c}\text { Pyrin } \\
\mathbf{5 0} \%\end{array}$ \\
\hline $\mathbf{1 0 0 0}$ & 31,783 & 35,237 & 77,922 & 152,830 & 13,023 & 16,799 & 12,508 \\
\hline $\mathbf{1 5 0 0}$ & 38,001 & 48,434 & 79,198 & 165,479 & 22,954 & 24,870 & 22,860 \\
\hline $\mathbf{2 0 0 0}$ & 38,338 & 71,585 & 97,513 & 208,166 & 60,209 & 37,725 & 47 \\
\hline
\end{tabular}

Table 14. The HC average value variation on different rpm regarding to the mixture

\begin{tabular}{|c|c|c|c|c|c|c|c|}
\hline & \multicolumn{7}{|c|}{ NO (ppm) } \\
\hline rpm & diesel & $\begin{array}{c}\text { Pyrin } \\
\mathbf{5 \%}\end{array}$ & $\begin{array}{c}\text { Pyrin } \\
\mathbf{1 0 \%}\end{array}$ & $\begin{array}{c}\text { Pyrin } \\
\mathbf{2 0} \%\end{array}$ & $\begin{array}{c}\text { Pyrin } \\
\mathbf{3 0} \%\end{array}$ & $\begin{array}{c}\text { Pyrin } \\
\mathbf{4 0} \%\end{array}$ & $\begin{array}{c}\text { Pyrin } \\
\mathbf{5 0 \%}\end{array}$ \\
\hline $\mathbf{1 0 0 0}$ & 518,210 & 415,212 & 375,075 & 392,478 & 372,681 & 473,620 & 362,663 \\
\hline $\mathbf{1 5 0 0}$ & 739,366 & 730,361 & 677,793 & 703,549 & 673,198 & 729,462 & 758,413 \\
\hline $\mathbf{2 0 0 0}$ & 762,155 & 790,676 & 738,929 & 805,702 & 825,376 & 938,210 & 880,990 \\
\hline
\end{tabular}

Table 15. The NO average value variation on different rpm regarding to the mixture

\begin{tabular}{|c|c|c|c|c|c|c|c|}
\hline \multirow{2}{*}{ rpm } & \multicolumn{7}{|c|}{ \%smoke } \\
\cline { 2 - 8 } & diesel & Pyrin 5\% & Pyrin 10\% & Pyrin 20\% & Pyrin 30\% & Pyrin 40\% & Pyrin 50\% \\
\hline $\mathbf{1 0 0 0}$ & 9,990 & 12,605 & 14,787 & 12,717 & 11,018 & 9,932 & 16,278 \\
\hline $\mathbf{1 5 0 0}$ & 7,363 & 11,967 & 10,594 & 13,715 & 12,575 & 13,285 & 19,673 \\
\hline $\mathbf{2 0 0 0}$ & 6,634 & 14,212 & 12,201 & 14,131 & 14,098 & 17,528 & 23,359 \\
\hline
\end{tabular}

Table 16 . The $\%$ smoke average value variation on different rpm regarding to the mixture 


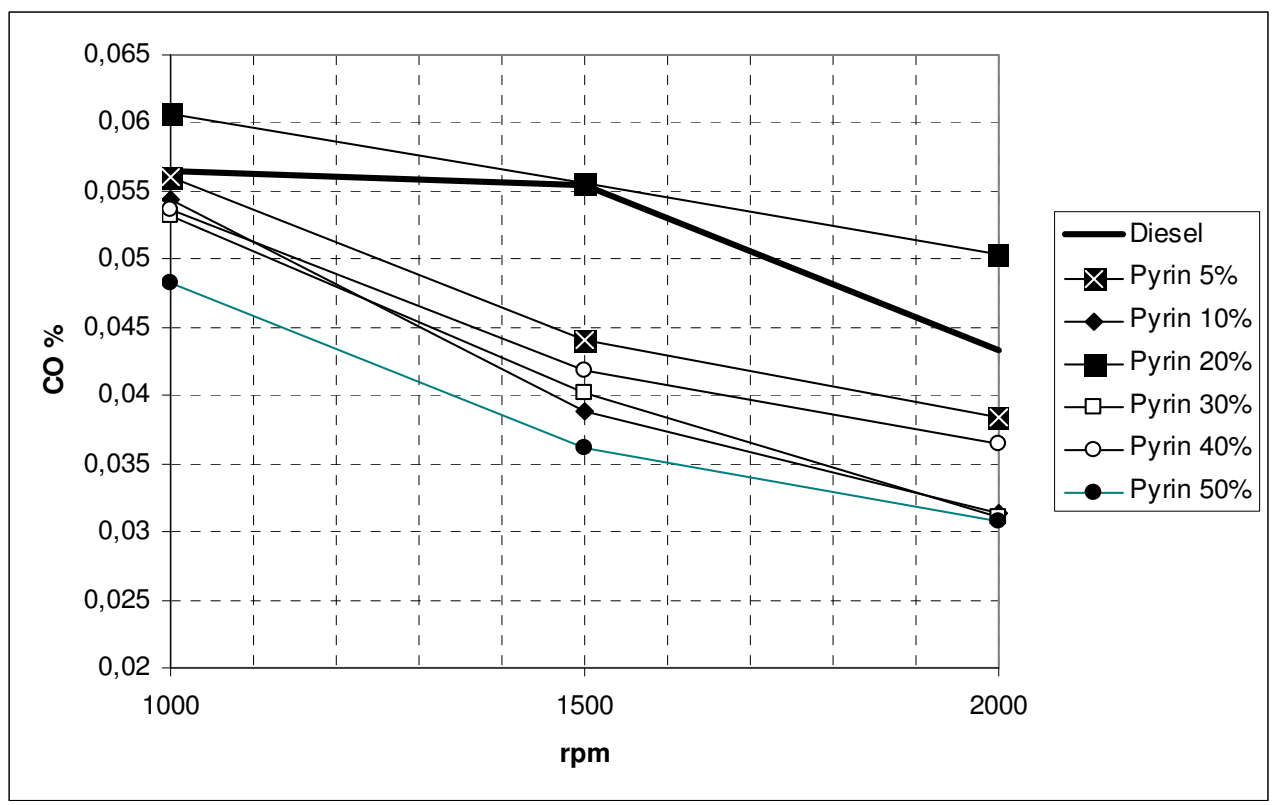

Fig. 14. The $\mathrm{CO}$ variation on different rpm regarding to the mixture

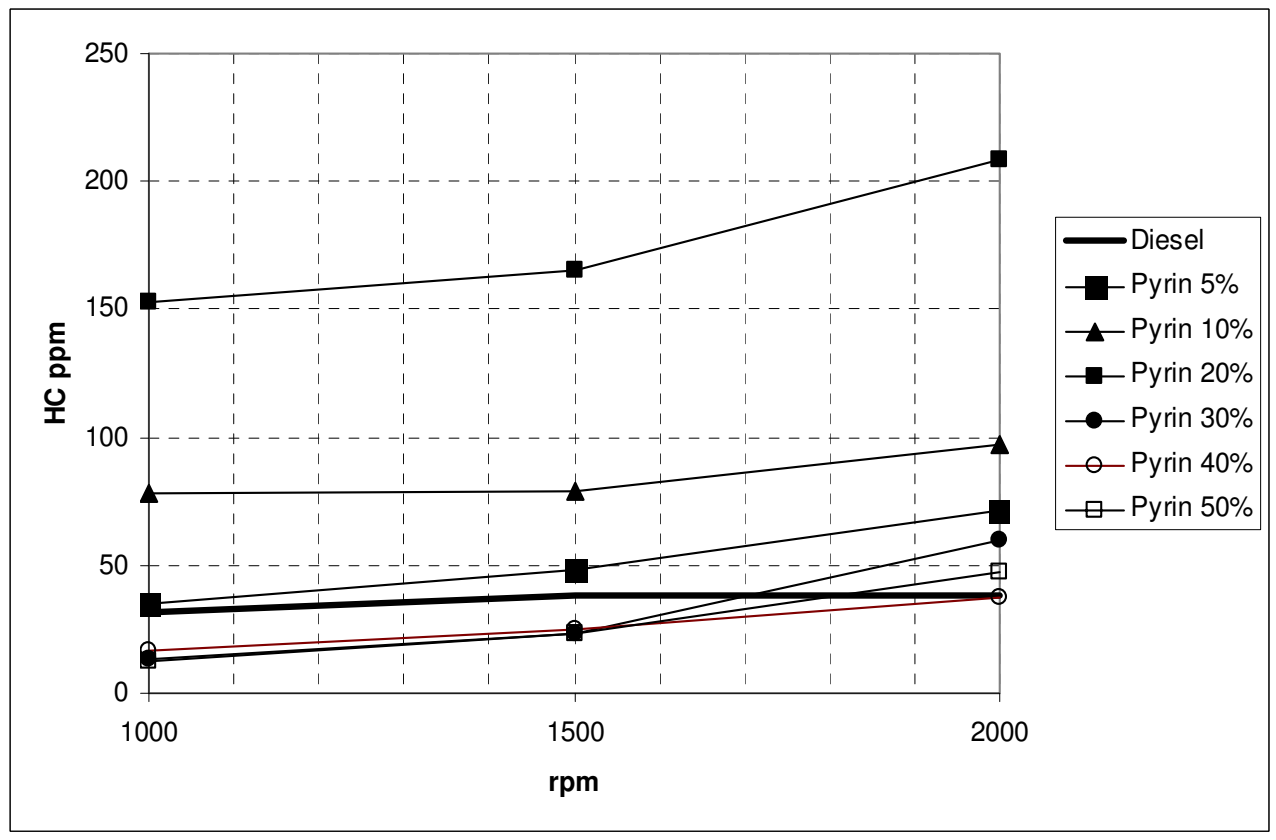

Fig. 15. The HC variation on different rpm regarding to the mixture 


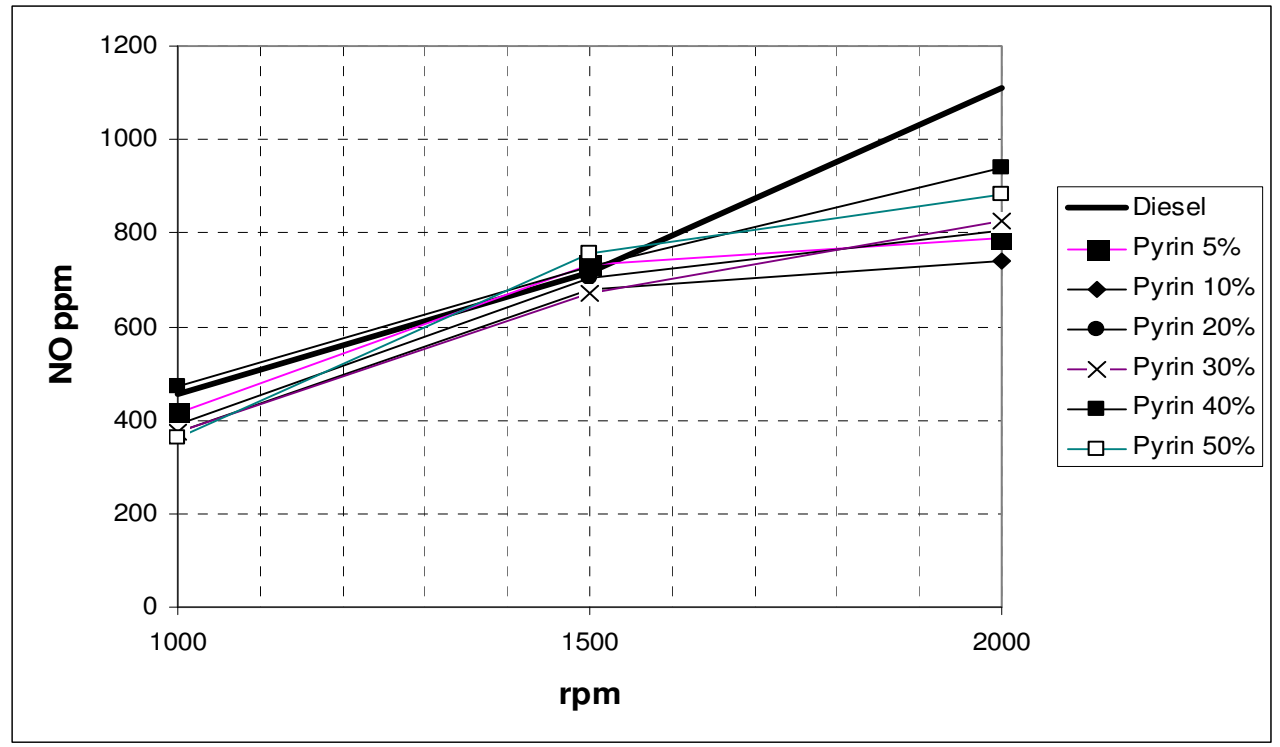

Fig. 16. The NO variation on different rpm regarding to the mixture

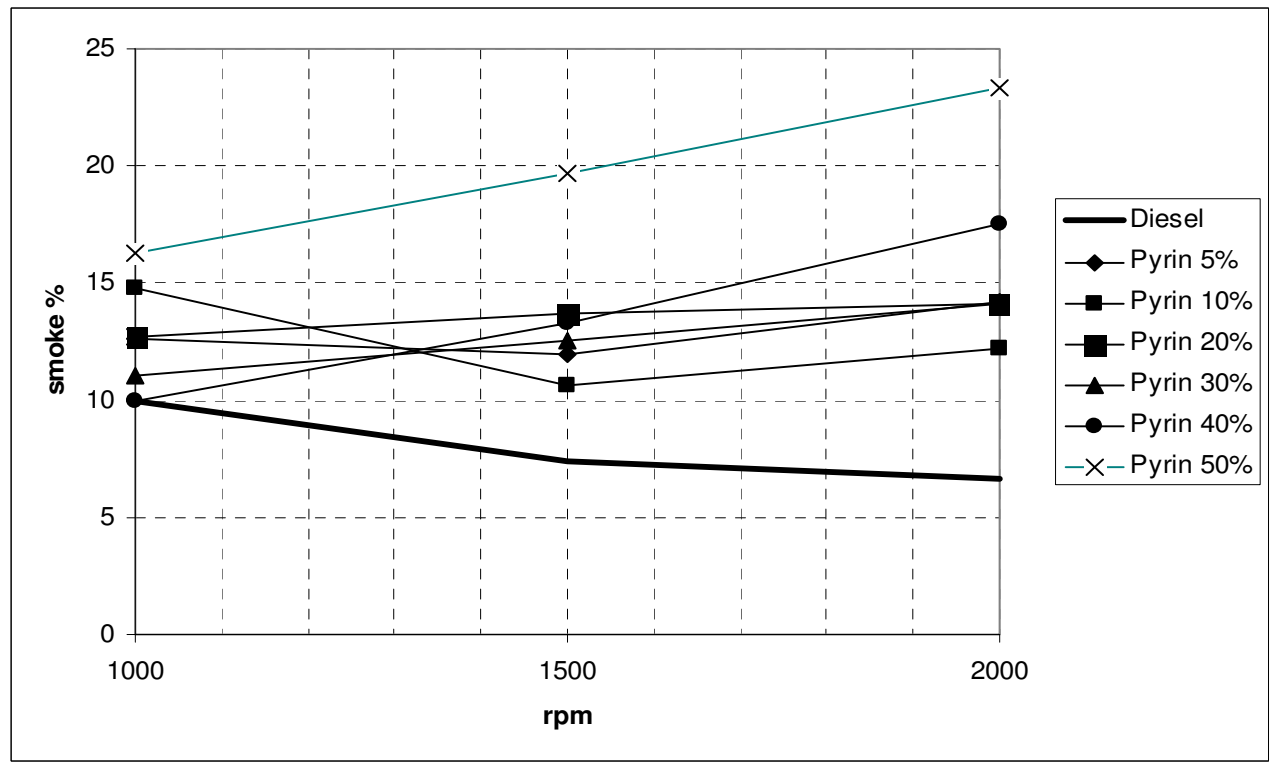

Fig. 17. The smoke variation on different rpm regarding to the mixture

From figure 14 it is clear that when the olive seed oil is increased on the fuel regarding to diesel, it appears a decrease of CO. From figure 15 it can be noticed the biggest reduction of HC regarding to diesel in case of pyrin $50 \%$. From figure 16 it can be noticed the biggest 
reduction of NO regarding to diesel in the case of pyrin10\%/2000rpm. From figure 17 it can be noticed that the best behaviour appears on diesel. From the above figures it is clear that the use of different mixtures can constitute changes to $\mathrm{CO}, \mathrm{HC}, \mathrm{NO}$ and smoke too. It is also important the fact that there was no changes in the rounds of the engine, as well as in the supply of water at the use of mixtures. Finally as far as the consumption is concerned, did not observed changes with the use of different mixtures. The use of mixture of diesel and olive seed oil has the following impacts:

- About CO it can be noticed when the olive seed oil is increased on the fuel regarding to diesel, it appears a decrease of $\mathrm{CO}$

- About HC it can be noticed the biggest reduction of HC regarding to diesel in case of pyrin $50 \%$

- $\quad$ The biggest reduction of NO regarding to diesel in the case of pyrin10\%/2000rpm.

- $\quad$ The smoke it can be noticed that the best behaviour appears on diesel.

\subsection{Soy oil}

In the experiment stage has been used directly soy oil in the mixture of diesel in to a four stroke Diesel engine. Specifically it has been used Diesel, mixture Diesel-5\% soy oil (S5), Diesel-10\% soy oil (S10), Diesel-20\% soy oil (S20), Diesel-30\% soy oil (S30), Diesel-40\% soy oil (S40), Diesel-50\% soy oil (S50) in a four-stroke diesel engine [20]:

The experimental results are shown at the following tables and figures:

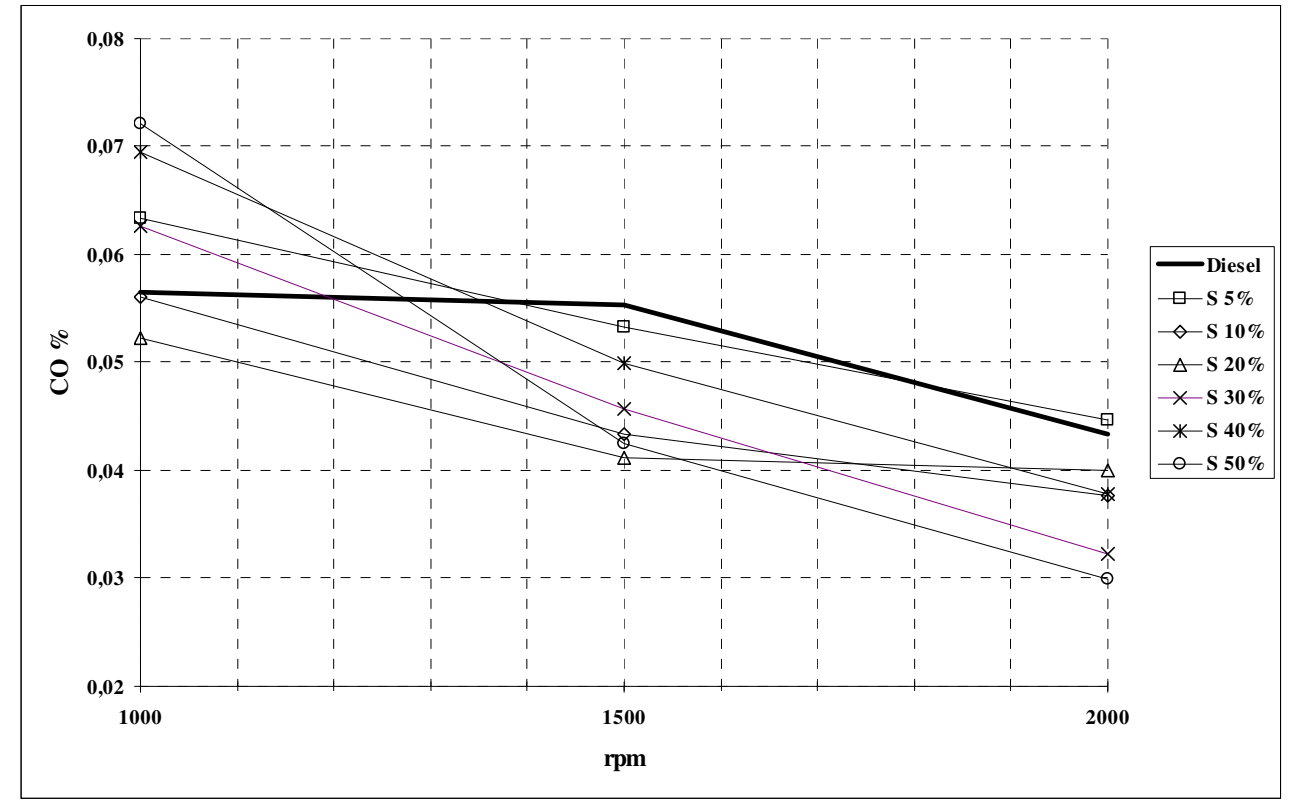

Fig. 18. The $\mathrm{CO}$ variation on different rpm regarding to the mixture

From figure 18 it is clear that when the soy oil is increased on the fuel regarding to diesel, it appears a decrease of CO, except in the cases S5,30,40,50/1000rpm. 


\begin{tabular}{|c|c|c|c|c|c|c|c|}
\hline \multirow{2}{*}{ rpm } & \multicolumn{7}{|c|}{ HC (ppm) } \\
\cline { 2 - 8 } & Diesel & S5 & S10 & S20 & S30 & S40 & S50 \\
\hline 1000 & 31,78 & 21,15 & 21,88 & 8,28 & 5,76 & 54,61 & 28,01 \\
\hline 1500 & 38,00 & 24,30 & 51,65 & 9,16 & 5,80 & 55,53 & 30,04 \\
\hline 2000 & 38,33 & 23,70 & 89,90 & 28,68 & 22,34 & 84,88 & 67,47 \\
\hline
\end{tabular}

Table 17. The $\mathrm{CO}$ average value variation on different rpm regarding to the mixture

\begin{tabular}{|c|c|c|c|c|c|c|c|}
\hline \multirow{2}{*}{ rpm } & \multicolumn{7}{|c|}{ NO (ppm) } \\
\cline { 2 - 8 } & Diesel & S5 & S10 & S20 & S30 & S40 & S50 \\
\hline 1000 & 454,2 & 387,6 & 397,5 & 416,1 & 414,8 & 341,0 & 277,9 \\
\hline 1500 & 715,3 & 739,8 & 743,6 & 720,9 & 758,8 & 718,8 & 651,1 \\
\hline 2000 & 1109,6 & 621,7 & 829,6 & 808,2 & 915,6 & 919,8 & 920,2 \\
\hline
\end{tabular}

Table 18. The HC average value variation on different rpm regarding to the mixture

\begin{tabular}{|c|c|c|c|c|c|c|c|}
\hline \multirow{2}{*}{ rpm } & \multicolumn{9}{|c|}{ \% smoke } & S50 \\
\cline { 2 - 8 } & Diesel & S5 & S10 & S20 & S30 & S40 & 24 \\
\hline 1000 & 9,99 & 8,72 & 9,41 & 11,61 & 14,26 & 18,32 & 17,84 \\
\hline 1500 & 7,36 & 8,23 & 8,43 & 9,87 & 13,02 & 18,21 & 20,5 \\
\hline 2000 & 6,63 & 6,25 & 7,70 & 8,08 & 11,27 & 17,21 & \\
\hline
\end{tabular}

Table 19. The NO average value variation on different rpm regarding to the mixture

\begin{tabular}{|c|c|c|c|c|c|c|c|}
\hline \multirow{2}{*}{ rpm } & \multicolumn{7}{|c|}{ CO \% } \\
\cline { 2 - 8 } & Diesel & S5 & S10 & S20 & S30 & S40 & S50 \\
\hline 1000 & 0,056 & 0,063 & 0,056 & 0,052 & 0,062 & 0,069 & 0,072 \\
\hline 1500 & 0,055 & 0,053 & 0,043 & 0,041 & 0,045 & 0,049 & 0,042 \\
\hline 2000 & 0,043 & 0,044 & 0,037 & 0,04 & 0,032 & 0,037 & 0,029 \\
\hline
\end{tabular}

Table 20. The $\%$ smoke average value variation on different rpm regarding to the mixture

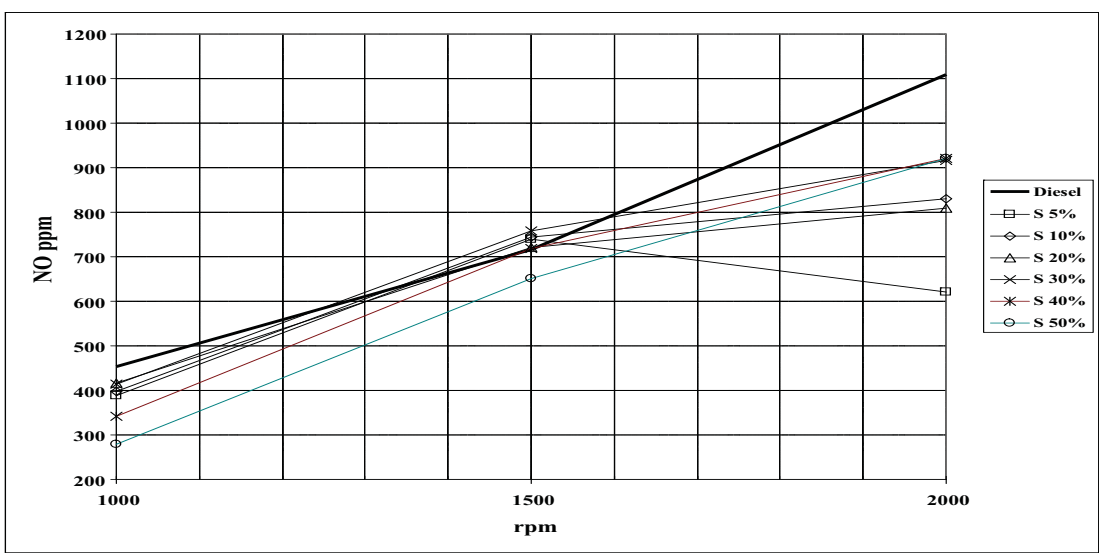

Fig. 19. The HC variation on different rpm regarding to the mixture 
From figure 19 it can be noticed the biggest reduction of HC regarding to diesel in case of the mixtures S5, S20 and the mixture S40.

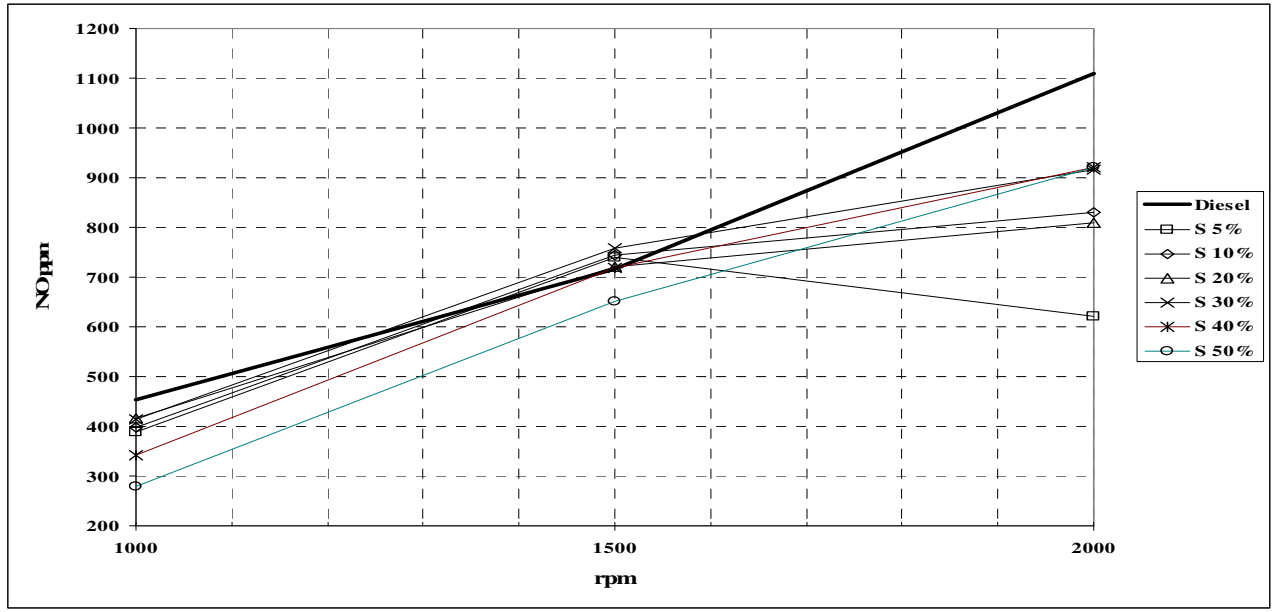

Fig. 20. The NO variation on different rpm regarding to the mixture

From figure 20 it can be noticed the biggest reduction of NO regarding to Diesel in the case of the mixture S50.

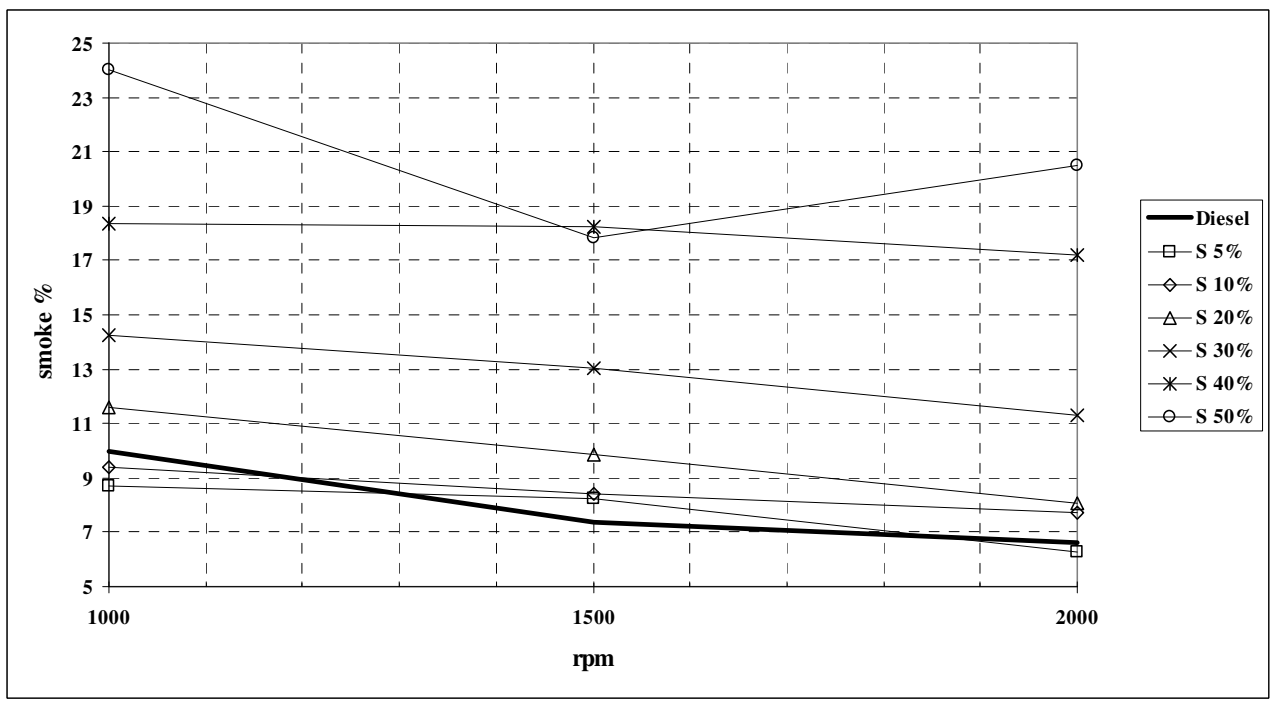

Fig. 21. The smoke variation on different rpm regarding to the mixture

From figure 21 it can be seen the increase of smoke regarding to diesel for all the mixtures. From the above figures it is clear that the use of different mixtures can constitute changes to $\mathrm{CO}, \mathrm{HC}, \mathrm{NO}$ and smoke too. It is also important the fact that there was no changes in the 
rounds of the engine, as well as in the supply of water at the use of mixtures. Finally as far as the consumption is concerned, did not observed changes with the use of different mixtures. The use of mixture of diesel and soy oil has the following impacts:

- About CO it can be noticed that when the soy oil is increased on the fuel regarding to diesel, it appears a decrease of CO, except in the cases S5,30,40,50/1000rpm.

- $\quad$ About HC it can be noticed the biggest reduction of HC regarding to diesel in case of the mixtures S5, S20 and the mixture S40.In the case of S30 appears the maximum increase of $\mathrm{HC}$ in relation to diesel.

- The biggest reduction of NO regarding to Diesel is noticed in the case of the mixture S50.

- The smoke is increased regarding to diesel for all the mixtures. Except the cases S5,50/1000rpm.

\section{References}

[1] Aldritton L, Monastersky R., Eddy A, Hall M, Shea E. (1992). Our Ozone Shield Reports to the Nation on Our Changing Planet. Fall 1992, University Cooperation for Atmospheric research office for interdisciplinary studies Boulder, Colorado.

[2] Arapatsakos C, (2000). Air and water influence of two stroke outboard engine using gasoline - ethanol mixtures, Transaction of SAE, Book SP-1565.

[3] Arapatsakos C, Karkanis A, Sparis P. Environmental Contribution of Gasoline- Ethanol Mixtures, WSEAS Transactions on Environment and Development, Issue 7, Volume 2, July 2006.

[4] Arapatsakos C, Karkanis A, Sparis P. Gas emissions and engine behavior when gasolinealcohols mixtures are used, cburnal of Environmental Technology, Vol. 24, pp. 10691077.

[5] Arapatsakos C. Testing the tractor engine using diesel - ethanol mixtures under full load conditions, International eburnal of Heat \& Technology, Vol. 19, n.1, 2001.

[6] Arapatsakos C, Christoforidis D, Karkanis A. The gas emissions variation of diesel engine from the combustion of used vegetable oils, Proceedings of International Conference on Energy and Environment, Cambridge 2009.

[7] Arapatsakos C., Christoforidis D, Karkanis A, Mitroulas D, Teka C. (2007). Test results from the use of cotton oil mixtures as fuel in a four-stroke engine, International journal of Energy and Environment, Issue3 Vol. 1, 2007.

[8] Arapatsakos C, Christoforidis D, Karkanis A, Mitroulas D. Fuel of diesel - olive seed oil mixture' International journal of energy Issue 3 vol 2, 2008.

[9] Arapatsakos C, Christoforidis D, Karkanis A, Mitroulas K. Soy oil as fuel in a four stroke engine, eburnal of wseas transactions on environment and development 2008.

[10] Arapatsakos C, Christoforidis D, Sarantitis G, Giannopoulos D. Fuel mixtures of dieselmaize oil International journal of energy Issue 3 vol 2, 2008

[11] Schafer F., Basshuysen R. V., (1995). Reduced Emissions and Fuel Consumption in Automobile Engines Published by SAE.

[12] Menrad H, Haselhorst M. Alcohol fuels, Monograph. Springer, New York, ISBN 3211816968, 1981.

[13] Harrington A.; Shishu C. A Single-Cylinder Engine Study of the Effects of Fuel Type, Fuel Stoichiometry and Hydrogen-to-Carbon Ratio on CO, NO and HC Exhaust Emissions, SAE-Paper 730476 
[14] Owen K, Coley T, (1995). Automotive Fuels Reference Book, (Second Edition), Published by SAE.

[15] Mitchell B. (1989). The greenhouse effect and climate change. Reviews of Geophysics 27.

[16] Arapatsakos C, Karkanis A, Sparis P, Gas emissions and engine behaviour when gasoline -alcohol mixtures are used, Environmental technology 24 (2003) 1069-1077.

[17] Siddharth S., Green Energy-Anaerobic Digestion. Converting Waste to Electricity, WSEAS Transactions on Environment and Development, Issue 7, Volume 2, July 2006.

[18] Swedish Motor Fuel Technology Co., Alcohols and alcohol blends as motor fuels, Vol. II B, p.8:39, STU information No 580,1986.

[19] Maxwell T, Jones C, (1995). Alternative fuels: Emissions, Economics and Performance Published by SAE.

[20] Schenewerk E, Automatic DRAC LMFBR to Speed Licensing and Mitigate CO2, WSEAS Transactions on Environment and Development, Issue 7, Volume 2, July 2006. 


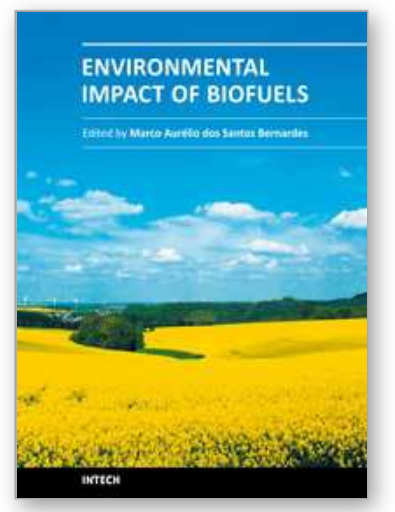

\author{
Environmental Impact of Biofuels \\ Edited by Dr. Marco Aurelio Dos Santos Bernardes
}

ISBN 978-953-307-479-5

Hard cover, 270 pages

Publisher InTech

Published online 06, September, 2011

Published in print edition September, 2011

This book aspires to be a comprehensive summary of current biofuels issues and thereby contribute to the understanding of this important topic. Readers will find themes including biofuels development efforts, their implications for the food industry, current and future biofuels crops, the successful Brazilian ethanol program, insights of the first, second, third and fourth biofuel generations, advanced biofuel production techniques, related waste treatment, emissions and environmental impacts, water consumption, produced allergens and toxins. Additionally, the biofuel policy discussion is expected to be continuing in the foreseeable future and the reading of the biofuels features dealt with in this book, are recommended for anyone interested in understanding this diverse and developing theme.

\title{
How to reference
}

In order to correctly reference this scholarly work, feel free to copy and paste the following:

Charalampos Arapatsakos (2011). Emissions of Diesel - Vegetable Oils Mixtures, Environmental Impact of Biofuels, Dr. Marco Aurelio Dos Santos Bernardes (Ed.), ISBN: 978-953-307-479-5, InTech, Available from: http://www.intechopen.com/books/environmental-impact-of-biofuels/emissions-of-diesel-vegetable-oilsmixtures

\section{INTECH}

open science | open minds

\section{InTech Europe}

University Campus STeP Ri Slavka Krautzeka 83/A 51000 Rijeka, Croatia Phone: +385 (51) 770447 Fax: +385 (51) 686166 www.intechopen.com

\section{InTech China}

Unit 405, Office Block, Hotel Equatorial Shanghai No.65, Yan An Road (West), Shanghai, 200040, China 中国上海市延安西路65号上海国际贵都大饭店办公楼405单元 Phone: +86-21-62489820

Fax: +86-21-62489821 
(C) 2011 The Author(s). Licensee IntechOpen. This chapter is distributed under the terms of the Creative Commons Attribution-NonCommercialShareAlike-3.0 License, which permits use, distribution and reproduction for non-commercial purposes, provided the original is properly cited and derivative works building on this content are distributed under the same license. 